\title{
Study on the Development Strategy of Airport Economy in Dalian
}

\author{
Shuxia Tan \\ City Institute of Dalian University of Technology, Dalian, China \\ Email: tanshuxia@126.com
}

How to cite this paper: Tan, S.X. (2020) Study on the Development Strategy of Airport Economy in Dalian. Modern Econo$m y, 11,200-207$.

https://doi.org/10.4236/me.2020.111017

Received: December 14, 2019

Accepted: January 28, 2020

Published: January 31, 2020

Copyright (c) 2020 by author(s) and Scientific Research Publishing Inc. This work is licensed under the Creative Commons Attribution International License (CC BY 4.0).

http://creativecommons.org/licenses/by/4.0/ (c) (i) Open Access

\begin{abstract}
In recent years, the airport's influence on economic development has become stronger. Airport economy has become the new engine of promoting regional economic development. As a resource-based city, Dalian has included the development of airport economy in Dalian's Development Plan, focusing on building airport economy circle, to make airport economy as an important section of driving regional economic development. SWOT stands for: strengths, weaknesses, opportunities, threats. The so-called SWOT analysis is based on the internal and external competitive environment and competitive conditions of the situation. The main internal advantages, disadvantages and external opportunities and threats that are closely related to the research object are listed through investigation, arranged according to the matrix form, and then analyzed with the idea of systematic analysis, from which a series of corresponding conclusions are drawn. In this context, this article analyzed the strengths, weaknesses, opportunities and threats of developing airport economy in Dalian, and proposed the strategic choice of the development of airport economy in Dalian.
\end{abstract}

\section{Keywords}

Airport Economy, Development, SWOT Analysis

\section{Introduction}

Airport economy is also called airport area economy, which is driven to the airport as the center around the economic development of certain areas, and this kind of development mainly reflected the surrounding areas of the airport like investment, consumption, labor and other aspects [1]. Airport industrial, airport services and airport ware-housing are the main industrial form of airport economic development. 
In the early 1980, Professor H. Weihrich who comes from the San Francisco University, first proposed SWOT analysis by strategic analysis. The principle is to investigate and analyze the strengths (S-Strengths), inferior (W-Weaknesses), opportunities (O-Opportunities) and threats ( $\mathrm{T}$-Threats) matrix according to some form of order to list them, and the system analysis of the idea and the arrangement of the combination of matrix elements, the system compatibility with the combination of various factors, and to find their advantage, taking advantage of opportunities to improve the weaknesses and respond to threats in the strategic plan. This paper first introduces the relevant meaning of the air-front economy, then analyzes the current situation of the development of the air-front economy in Dalian, and then uses SWOT analysis to analyze the internal advantages, disadvantages, external threats and opportunities of the development of the air-front economy in Dalian.

\section{The Advantage of Dalian Airport Economic Development}

In recent years, with the rapid economic development of Dalian, Dalian Airport Economy has more and more obvious advantages, and it mainly can be seen from the following aspects.

\subsection{Advantage of Location}

Dalian Airport is the designated alternate airport, international flights, is located in the old industrial bases in Northeast China. Dalian is the most places which provide air transport operations. Dalian is a major portion Northeast China, but also a cargo flow distribution center. 20 year of reform and opening up the economy of Dalian has laid a good foundation and environment for foreign investment. At present, Dalian has formed the Dalian Economic and Technological Development Zone, Dalian Free Trade Zone, Golden Pebble Beach National Holiday Resort, high-tech industrial park of Qixianling, Dalian, Hong Kong and other double-D with a considerable scale, multi-tiered opening pattern.

\subsection{Economic Advantage}

Dalian's economy is developing fast [1], and it is also very abundant in economic strength. By 2016, the GDP of Dalian is 1611.4 billion yuan, just 85.4 billion lower than Shenyang. At the same year, the GDP of Ganjingzi District, where the Zhoushuizi international located has increased at a speed of $18 \%$ higher than $15 \%$ of Dalian City, the average level of the whole, the main city of Dalian is located (see Table 1). in Dalian International Airport fully rely on the unique advantages and strengthen domestic and international economic and trade cooperation, to develop export-oriented industries, and city convention and exhibition industry, service outsourcing industry, modern logistics industry, to gradually build "airport economic zone"; growing high-tech industry Building high-tech industrial parks be improved and speed up the completion of "high-tech economic zones". Dalian City, these economic advantages, lays the development of airport economy to a certain foundation. 
Table 1. The GDP of the district of Dalian, in 2016.

\begin{tabular}{ccc}
\hline District & GDP (billion yuan) & Rate \\
\hline Dalian City & 1611.33 & $15 \%$ \\
Zhongshan District & 683.58 & $15.1 \%$ \\
Xigang District & 108 & $15 \%$ \\
Shahekou District & 372.4 & $15 \%$ \\
Ganjingzi District & 890.06 & $18 \%$ \\
Jinzhou District & 1611.33 & $15.5 \%$ \\
Lvshunkou District & 244.8 & $26.4 \%$ \\
\hline
\end{tabular}

\subsection{Transportation Advantage}

Dalian is convenient in transportation [2], such as sea and air transport networks, has formed a strong three-dimensional transport capacity of the modern transportation network. Dalian port is in more than 70 existing berths, of which 40 million tons of berths, with more than 160 countries and regions, more than 300 ports in trade and transport exchanges. Northeast China has undertaken more than $70 \%$ and $90 \%$ of sea cargo container transport, sea transport network-intensive, not only to Shanghai, Tianjin, Yantai, Weihai and cities such as Inchon passenger service, as well as access to the United States, Japan, India and other countries and regions, more than 40 international cargo routes; Dalian to Yantai Railway Ferry Project has begun operations. Dalian land transportation is very convenient. Railway and the North, Northeast railway network linked; road line extending in all directions; Dalian Zhoushuizi International Airport opened hundreds of international and domestic routes, is the largest in Northeast China's air cargo base. Dalian has been formed in water, land, air and complete three-dimensional traffic system [3].

\subsection{Great Potential of Airport Passenger Source Market}

Since 2003, Dalian Airport passenger throughput is to a rate of 100 million per year, during seven years, 192\% cumulative growth. 2010 Dalian Airport passenger throughput exceeded 10 million passengers. 2015, Dalian Airport passenger throughput will reach 20 million passengers, cargo and mail handling capacity of 25 tons. To 2020, passenger throughput reached 3000 - 3200 Dalian Airport million to 35 - 40 million tons of cargo and mail throughput 2030, Dalian Airport passenger throughput to reach 5800 - 6800 million 80 - 100 million tons of cargo and mail throughput, therefore, jumped around the air transport industry, the development of the overhead, will be the fastest growing industries.

\section{The Disadvantage of Dalian Airport Economic Development}

\subsection{Lack of Directivity Industry}

Today, the industrial advantage in Dalian is mainly concentrated in four main areas: the petro chemical industry, machine-building, ship-building, and soft- 
ware. If the machinery manufacture in and ship-building into equipment manufacturing, the industry will become the largest industry in Dalian, followed by the petro chemical industry. Even as a beautiful city, the development of the petro chemical industry are not suitable for the development of the whole city, including equipment manufacturing, including heavy chemical industry also not eligible to become the focus of future development. However, these industries do not have obvious directivity, and then restrict the development of Dalian air-front economy.

\subsection{Development and Utilization of Airport Economic Zone Is Still Small-Scale}

Internationally, many countries and regions have attached great importance to major international airports around the development and construction, including industrial zones, logistics parks, free zones and business zones, such as the Orlando International Airport, the French Charles de Gaulle International Airport. With these international airports on the regional economic and social impact than the Dalian Zhoushuizi airport economic zone around the airport development and utilization of the scale is still small, the features have to be perfect, of Dalian City, the role of economic and social development to be further excavated.

\subsection{Airport Economic Zone and the Existing Industrial Structure Irrational Industrial Distribution}

Dalian airport economic zone industry association is not strong [4], some large multinational corporations in the core area and the airport economic zone of radiation is not airport economy of raw materials, parts and components supporting enterprises, other enterprises lack the region's leading role. Overall, rational industrial community and the industry chain have not yet formed, airport economic zone of industrial layout is also not reasonable. On the surrounding area of the airport radiation weakens with increasing distance, the airport should be around the circle structure invading industry model. Dalian airport economic development in the process of optimal all location of land resources is not obvious, the zone failed to give full play to advantages of scale.

\subsection{No Reasonable Airport Economic Zone Traffic Planning}

Airport economy depends on the rapid accessibility of the airport-specific, therefore, improve the efficient ground transportation airport economic zone is the basic condition for development, and only have a good ground transportation network, airport economic zone to ensure the unimpeded flow of goods with the outside world. Although Zhoushuizi airport railway station and close to a number of bus lines, but for high-tech industry is concerned, whether in the shortest possible time, in order to minimize the cost of the product shipped to the airport, and then shipped around the world is the key factor in the competition. Dalian airport economic zone in this regard remains to be improved. 


\section{The Opportunities Analysis of Airport Economic Development in Dalian}

\subsection{The Transfer of International Industry Strongly Promote the Adjustment of Industrial Structure}

The progress of international industry transferring to China and the expansion of domestic capital in developed areas to the North is increasing with day, which provides an opportunity for undertaking industrial transfer, and attracting foreign investment to Dalian, and high-tech industry and modern service industry, increasingly become the focus of international industrial transfer. Dalian airport-related economy can take full advantage of international industrial transfer historical opportunities, to develop new industry, such as, outsourcing, service, a further promotion of industrial structure optimization, the improvement of international competitiveness of cities.

\subsection{Export-Oriented Economy Brought Better Development Opportunities}

Dalian export-oriented economy is highlighted [5], and there is a great demand on the international freight market potentials. During the period of twelfth five, the demand of international air freight is over 300,000 tons. Dalian airport will take the measures of introducing strong airlines, building a transportation network, to expand air cargo transshipment market, to strengthen the plan and construction of transportation infrastructure and other measures and to be coordinated and improved.

\subsection{China Southern Airlines, Hainan Airlines and Air China Jointly Promote Dalian Airport-Related Economy}

During the period of twelfth five, Dalian airport airlines will strengthen the based airport company, Strengthen hub run and construct comprehensive transportation system. Creating " $3+1+1+1$ " air base pattern, that is, to form a " $3+1+1+1$ " pattern of 3 main air base which is composed of China Southern Airlines, Hainan Airlines, Air China's Dalian, Dalian branch company, one extension base, 1 cargo base and one business jet base. Introducing regional airlines, building air extension base, focusing on the radiation of the North, Inner Mongolia and Bohai Bay area, connecting the main lines with the branch lines well, introducing cargo airlines, building air cargo base, to form a comprehensive freight routes network. Attracting business jet services operator and business Jet Company to set up corporate jet operations at the Dalian airport base, to develop Dalian business jet market.

\section{The Treat Analysis of Dalian Airport-Related Economy Development}

\subsection{Branch Services of Liaoning Province Snatches the Market}

Judging from the overall development of civil aviation [6], some major aviations 
hub and the main airports have been saturated at present. CAAC also has begun to actively promote the development of regional aviation, and led airport companies to fly to the second-tier cities in China, or, in the West. The running condition of regional airports in Liaoning province is not normalized. Although they are regional airports, but the flight is flight route, not only sail for distant, and passed and flew in some big cities.

The analysis of internal advantages is embodied in the following four aspects: first, Dalian Airport has a location advantage; second, the regional economic advantage is relatively obvious; third, the traffic advantage is prominent; fourth, the airport passenger supply market machine and tools potential. The internal disadvantages are mainly reflected in four aspects: first, the lack of directivity industry; secondly, there is no large-scale development and utilization of the air-front economic zone; thirdly, the industrial structure and industry lack of rational layout; finally, the traffic planning is not reasonable. The external threat is mainly reflected in three aspects: the increasingly fierce competition for the aviation market by regional flights in the province; the competition for the surrounding airports and ports and the high-speed rail. External development opportunities are mainly reflected in the following three aspects: first, the emergence of international industrial transfer opportunities; second, the export-oriented economy to bring better opportunities; third, a number of airlines cooperation opportunities.

\subsection{Facing Competition from around the Airport and Port}

Dalian and Shenyang airport are not in a far distance, what's more, the region barrier of Dalian and its surrounding cities is serious, competition surpassed cooperation, causing the association of industries of the two places to be small, lacking of effective integration of the tourism and aviation resources, not forming to each led industry chain, which has become the principal contradiction in restricting the economic development of Dalian airport.

Bohai Bay of Qingdao port, Tianjin Port in Northeast Asia ports competitiveness are not less than that in Dalian, what's more, Japan Yokohama, Korea Pusan and Guangyang port which is under construction, are all natural enemies of Dalian. The problem Dalian must face up with is that in the plan of Dandong and Yingkou port of "large Shenyang", because of the lack of a clear division, there would have inevitably competition for resources between ports, then formed duplicated construction, it is difficult to form a ports development in Liaoning province.

\section{The SWOT Analysis and Strategic Choice of Dalian Airport's Economic Development}

According to the internal advantages and disadvantages and external opportunities and threats analysis, we select four strategies which can make the most of Dalian advantages and opportunities and minimize the effects of weaknesses and threats (see Table 2 as follows). 
Table 2. SWOT matrix analysis table of airport economy of Dalian.

\begin{tabular}{|c|c|c|c|}
\hline & \multicolumn{2}{|l|}{ Analysis of externality } \\
\hline & & Opportunity O & Threat $\mathrm{T}$ \\
\hline \multirow{2}{*}{$\begin{array}{l}\text { Analysis } \\
\text { of } \\
\text { internality }\end{array}$} & Superiority $\mathrm{S}$ & $\begin{array}{l}\text { SO stratagem: } \\
\text { Government steps up planning } \\
\text { airport-related economy }\end{array}$ & $\begin{array}{l}\text { ST stratagem: } \\
\text { Coordinating and producing } \\
\text { resource advantages, dislocation } \\
\text { development }\end{array}$ \\
\hline & Weakness W & $\begin{array}{l}\text { WO stratagem: } \\
\text { Relying on international industry } \\
\text { transfer opportunities developing } \\
\text { aerospace manufacturing and } \\
\text { logistics }\end{array}$ & $\begin{array}{l}\text { WT stratagem: } \\
\text { Establishing regional development } \\
\text { coordination bodies and mechanism }\end{array}$ \\
\hline
\end{tabular}

In short, to promote the development of Dalian airport-related economy, the government must seize time planning airport-related economy, and positively integrate resources, play advantage and develop appositions. Dalian airport economic development should be based on international industry transfer opportunities, develop aerospace manufacturing and logistics, and the establishment of institutions and mechanisms for coordinated development of regional economy. Led by the above-mentioned, Dalian airport-related economy will be fully developed.

\section{Funding}

Projects funded by the Liaoning Provincial Social Science Foundation-A study on the coordinated development of airport economy and regional economy in Liaoning (L18BJY015).

\section{Conflicts of Interest}

The author declares no conflicts of interest regarding the publication of this paper.

\section{References}

[1] Yang, J.L., David, H., Pete, D., et al. (2011) The Use of Cessation Assistance among Smokers from China: Findings from the ITC China Survey. BMC Public Health, 11, 75. https://doi.org/10.1186/1471-2458-11-75

[2] Cao, Y.C. and Xi, Y.R. (2009) Airport-International Experience and Its Reference to China's Economic Development. Modernization of Shopping Malls, No. 2, 244-246.

[3] DePina, J.J., Dia, A.K., de Ascenção Soares Martins, A., et al. (2019) Knowledge, Attitudes and Practices about Malaria in Cabo Verde: A Country in the Pre-Elimination Context. BMC Public Health, 19, 850. https://doi.org/10.1186/s12889-019-7130-5

[4] Gu, Y.J., Fu, L.P. and Liu, X.F. (2007) Discussion on the Development of Airport-Related Economy in New Coastal Area. Development and in the Future, No. 9, 63.

[5] Belay, D.B., Kifle, Y.G., Goshu, A.T., et al. (2017) Joint Bayesian Modeling of Time to Malaria and Mosquito Abundance in Ethiopia. BMC Infectious Diseases, 17, 415. 
https://doi.org/10.1186/s12879-017-2496-4

[6] Chen, Y., Rennie, D.C., Karunanayake, C.P., et al. (2015) Income Adequacy and Education Associated with the Prevalence of Obesity in Rural Saskatchewan, Canada. BMC Public Health, 15, 700. https://doi.org/10.1186/s12889-015-2006-9 